\begin{tabular}{|l|l|}
\hline Postprint Version & 1.0 \\
\hline Journal website & $\underline{\text { http://www.springerlink.com/content/105587/ }}$ \\
\hline Pubmed link & $\begin{array}{l}\text { http://www.ncbi.nlm.nih.gov/entrez/query.fcgi? } \mathrm{cmd}=\text { Retrieve\&db=pubmed\&dop } \\
\mathrm{t=Abstract \& list} \text { uids=15626322\&query hl=45\&itool=pubmed_docsum }\end{array}$ \\
\hline DOI & \begin{tabular}{l}
$10.1023 / \mathrm{B}:$ CHUD.0000039317.50547.e3 \\
\hline
\end{tabular}
\end{tabular}

Address correspondence to M. Morren, Department of Medical, Clinical, and Experimental Psychology, Maastricht University, P.O. Box 616, 6200 MD Maastricht, The Netherlands; e-mail: M.Morren@dep.unimaas.nl.

\title{
Emotional Reasoning and Parent-based Reasoning in Normal Children
}

\author{
Mattijn Morren, MSc; Peter Muris, PhD; Merel Kindt, PhD
}

Department of Medical, Clinical and Experimental Psychology, MaAstricht University, The Netherlands

\begin{abstract}
:
A previous study by Muris, Merckelbach, and Van Spauwen1 demonstrated that children display emotional reasoning irrespective of their anxiety levels. That is, when estimating whether a situation is dangerous, children not only rely on objective danger information but also on their own anxiety-response. The present study further examined emotional reasoning in children aged $7-13$ years $(\mathrm{N}=508)$. In addition, it was investigated whether children also show parent-based reasoning, which can be defined as the tendency to rely on anxiety-responses that can be observed in parents. Children completed self-report questionnaires of anxiety, depression, and emotional and parent-based reasoning. Evidence was found for both emotional and parent-based reasoning effects. More specifically, children's danger ratings were not only affected by objective danger information, but also by anxiety-response information in both objective danger and safety stories. High levels of anxiety and depression were significantly associated with the tendency to rely on anxiety-response information, but only in the case of safety scripts.
\end{abstract}

Childhood fears are considered as an integral and adaptive part of normal development in reaction to real or imagined threat. ${ }^{2}$ These fears wax and wane as children become older, and although they usually disappear in due course, in some children they persist and come to interfere with daily functioning. ${ }^{3}$ Epidemiological studies found that the prevalence of anxiety disorders in children and adolescents varies between 5.7 and $17.7 \%$ in community samples. ${ }^{4}$ Researchers and clinicians in the field of child and adolescent psychopathology have recently reached consensus on the anxiety disorders that may occur in children and adolescents. ${ }^{5}$ The most common childhood anxiety disorders are social anxiety, separation anxiety disorder, and generalized anxiety disorder. According to Kendall's ${ }^{6}$ theory of childhood fear and anxiety, anxiety disorders result from overactive danger schemas. These overactive schemas are presumed to chronically focus processing resources on threatrelevant information. This gives rise to erroneous cognitive processing - i.e., cognitive distortions - that produce maladaptive or dysfunctional thoughts and behaviors. Crick and Dodge's ${ }^{7}$ information- processing model allows that distinctive cognitive distortions emerge during different stages of information processing. ${ }^{8}$ One example of a cognitive distortion is interpretation bias, which reflects children's tendency to attribute threatening meaning, intent, or outcome expectations to ambiguous situations. ${ }^{8}$ 
Emotional reasoning is a form of interpretation bias that was first described by Beck, Emery, and Greenberg", who observed that "Many anxious patients use their feelings to validate their thoughts and thus start a vicious circle: 'I'll be anxious when I ask for the date so there must be something to fear." (p. 198). In other words, anxiety patients not only rely on objective information to determine the danger status of an event, but also on information provided by their own anxiety response. Arntz, Rauner, and Van den Hout ${ }^{10}$ experimentally examined this phenomenon, and found evidence for emotional reasoning in spider phobics, panic patients, social phobics, and patients with other anxiety disorders. However, these emotional reasoning effects were not content-specific: that is, specific anxiety complaints could not be linked to emotional reasoning in disorder-specific situations. Similar findings were obtained with PTSD patients who appeared to infer danger from both their own anxiety responses and their intrusions. ${ }^{11,12}$ Thus, it seems that anxious subjects strongly act on the proposition: "If I feel anxious, there must be danger."

Muris, Merckelbach, and Van Spauwen ${ }^{1}$ recently examined the emotional reasoning phenomenon in children. Normal primary school children $(N=101)$ were exposed to scripts that systematically combined objective danger and objective safety situations with or without anxiety-response information. The scripts described situations related to social phobia, separation anxiety disorder, and generalized anxiety disorder, and children were asked to provide danger ratings for the pertinent scripts. The authors found some support for a general emotional reasoning effect. That is, danger ratings to objective safety scripts were inflated when anxiety-response informa tion was included. In addition, emotional reasoning was significantly associated with both trait anxiety and anxiety sensitivity in objective safety situations. Comparable results were obtained in a second study of normal school children $(N=156)$. In that study, Muris, Merckelbach, Schepers, and Meesters ${ }^{13}$ found that anxiety-response information enhanced children's perception of threat. It should be noted, however, that these findings are at odds with Arntz et al. ${ }^{10}$ and Engelhard et al., ${ }^{11,12}$ who showed that such emotional reasoning effects are absent in normal adults. Thus, whereas normal adults merely rely on objective danger information when estimating the dangerousness of hypothetical scenarios, normal children seem to resemble anxious adults in their additional use of anxiety-response information to evaluate threat.

These findings seem to suggest that emotional reasoning in children is not necessarily a pathological phenomenon. ${ }^{1}$ It is plausible that emotional reasoning constitutes a normal characteristic of development that may serve to protect children from potential threats. Anxiety responses may sensitize children to potential danger even under rather harmless circumstances, which chimes in with the high prevalence of specific fears in children. ${ }^{14}$ Normally, children would gradually learn to neglect these anxiety responses and increasingly rely on objective danger information, and the emotional reasoning heuristic will be disengaged. Failure of this learning process would lead to an increased risk for developing an anxiety disorder. ${ }^{15}$

Interestingly, a similar developmental pattern has been proposed for another type of information processing bias, namely attentional bias. In a study by Kindt, Brosschot, and Everaerd, ${ }^{16}$ attentional bias was found to be present in young children irrespective of their fear level. From about age 11, this bias seemed to decrease in nonfearful children, whereas it persisted in fearful children. ${ }^{17}$ This finding was replicated in subsequent studies. ${ }^{18,19}$ If emotional reasoning in children follows a similar developmental pattern, its relationship with anxiety can be expected to change with age. That is, emotional reasoning will wane with age in non-anxious children, but will persist in anxious children.

If it is assumed that emotional reasoning follows such a differential pattern, the question would be, of course, what factors are involved in the disappearance or persistence of this phenomenon? Relevant in this context may be the process of social referencing, which is defined as the tendency to make appraisals of a stimulus based on one's perception of another person's response to this stimulus. ${ }^{20}$ Children frequently use their parents as the main source for social referencing, and there is indeed evidence showing that young children react with fear and avoidance to novel stimuli after having observed their mothers' negative affective response. ${ }^{21-24}$ The process of social referencing bears strong resemblance to modeling, which is generally considered as one of the three pathways to the development of fear and anxiety. ${ }^{25-27}$ Thus, children may not only estimate danger on the basis of their own anxiety response (i.e., emotional reasoning), but perhaps use their parents' response as well (i.e., parent- based reasoning). 
In sum, the present study investigated (1) whether children aged 7-13 years exhibit emotional and parent-based reasoning in response to objective danger and objective safety situations, (2) whether higher levels of anxiety and depression are associated with a greater tendency to infer danger from personal and parent anxiety-response information, and (3) whether anxiety, to a greater degree than depression, is associated with this tendency. Furthermore, it was examined (4) whether emotional reasoning is content-specific: that is, are specific anxiety symptoms (i.e., social anxiety, separation anxiety, and generalized anxiety) linked to emotional reasoning in response to stories depicting disorder-specific situations. Finally, the present study examined (5) whether emotional and parentbased reasoning show the predicted developmental pattern (i.e., decrease in non-anxious children, persistence in anxious children).

\section{METHODS}

\section{Participants}

The present study was part of the one-year follow-up of an ongoing project investigating the relationship between spider fear and processing bias. ${ }^{28}$ The project initially enrolled 580 children selected from 3564 children on the basis of spider fear.* Children attended regular primary schools in the Southern part of the Netherlands. Information about children's socioeconomic status was not available. However, schools were situated in urban and rural areas, in neighborhoods with varying socioeconomic status. Informed consent had been obtained at baseline from a primary caretaker who stated that the child was allowed and wanted to participate in the study. All children were still willing to participate when the assessment took place. Attrition reduced the present sample with $12 \%$ to 508 chil- dren (424 girls), mainly because children refused further participation or could not be contacted. Mean age of the children was 10.6 years $(S D=1.4$; range 7.7-13.9 years), and boys and girls did not differ significantly in age, $t(506)<1, p=0.9$. There were 61 children aged 7/8, 127 aged 9,108 aged 10,107 aged 11, 84 aged 12 , and 21 aged 13 years.

\section{Materials}

Questionnaires. The short version of the Revised Children's Anxiety and Depression Scale $(\text { RCADS })^{30}$ is derived from Chorpita, Yim, Moffitt, Umemoto, and Francis' scale ${ }^{31}$ using exploratory and confirmatory factor analysis. The 25-item RCADS can be used to assess symptoms of generalized anxiety disorder (e.g., "I worry about bad things happening to me"), separation anxiety disorder (e.g., "I fear being away from my parents"), social phobia (e.g., "I am afraid to talk in front of the class"), panic disorder (e.g., "My heart suddenly beats too quickly for no reason"), and major depressive disorder (e.g., "I feel that nothing is much fun anymore"). Each subscale contains five items that are answered on a four-point scale: $0=$ never, $1=$ sometimes, $2=$ often, $3=$ always. Subscale scores can be obtained by summing relevant items. In addition, a total anxiety symptoms score is computed by summing scores of the four anxiety subscales. Reliability and validity of the RCADS are both good. ${ }^{30}$ The trait anxiety scale of the State-Trait Anxiety Scale for Children (STAIC) ${ }^{32}$ is a 20-item measure of chronic anxiety symptoms such as "I get a funny feeling in my stomach" and "I am scared". Children rate how often they experience each anxiety symptom on a three-point scale ( $1=$ almost never, $2=$ sometimes, and $3=$ often). Summed item ratings produce a total trait anxiety score (range 20-60), with higher scores being indicative of higher levels of trait anxiety.

Stories. Stories were based on the stories of two previous studies investigating emotional reasoning in children ${ }^{1}$ and adults. ${ }^{10}$ In both studies, an emotional reasoning effect was identified by means of this story material.

In the present study, the stories portrayed four situations that children may experience, pertaining to the following themes of anxiety: (1) social anxiety story: talking in front of the class, (2) separation

\footnotetext{
* Spider fear was measured using the Spider Phobia Questionnaire for Children29, which contains 29 true-false items. The scale has been shown to be a good predictor of fear behavior in confrontation to a spider.
} 
anxiety story: taking the subway with parents on holidays abroad, (3) generalized anxiety story: getting your report card from the teacher, and (4) parent anxiety story: traversing a pedestrian crossing with your mother. There were four versions of each story: (a) with objective danger information and subjective anxiety-response information, (b) with objective danger information and subjective positive-response information, (c) with objective safety information and subjective anxiety-response information, and (d) with objective safety information and subjective positive-response information. Great care was taken that the wording of different versions of a story were as similar as possible, apart from the descriptions of danger and response information. Table 1 shows the anxiety- and positiveresponse information that was included in the stories.

The 16 stories were presented in paper-and-pencil format. The order of presentation was fixed random with the restriction that two stories describing the same situation, or the same objective danger or response information did not follow each other. To reduce the possibility of systematic order effects, the stories were counterbalanced: half of the children first received stories $1-8$ followed by stories 9-16, whereas this order was reversed for the other half of the children.

Children were instructed to read each story carefully. They were encouraged to imagine that they were the leading character of the story and that they were actually confronted with the events that the stories described. Children were asked to indicate how dangerous they found each story on a scale from 1 (not at all dangerous) to 10 (very dangerous).

\section{Procedure}

All children from one and the same school completed the questionnaires (RCADS and STAIC) and stories together in a separate room at school. The experimenter was always available to provide assistance when necessary.

\section{Statistical Analysis}

The Statistical Package for Social Sciences (SPSS) was used for data analysis. Missing values on questionnaires were replaced with the mean of a child's summed valid item score on a particular questionnaire (or subscale) if less than $10 \%$ was missing. When more than $10 \%$ were missing, the particular questionnaire sum score was discarded from the analyses. As a result, $N$ s varied across analyses. To examine general emotional reasoning effects, danger ratings for the same version of the social, separation, and generalized anxiety stories were averaged. Danger ratings to the child and parent anxiety stories were subjected to separate 2 (Situation: objective danger versus objective safety) $\times 2$ (Response: anxiety-versus positiveresponse) analyses of variance (ANOVAs).

To investigate the association between emotional and parent-based reasoning, on the one hand, and anxiety symptoms, on the other hand, a number of calculations were made. First, difference scores were computed by subtracting ratings for stories containing positive-response information from ratings for similar stories containing anxiety-response information, both for objective danger (i.e., danger scores) and objective safety stories (i.e., safety scores). In addition, index scores were obtained by averaging safety and danger scores. Subsequently, gender-corrected correlations were computed between danger ratings, danger, safety, and index scores for the child and parent anxiety stories, on the one hand, and anxiety and depression symptoms (RCADS) and trait anxiety (STAIC), on the other hand. Relationships of anxiety and depression with emotional and parent-based reasoning were examined by comparing the magnitude of correlations. In addition, specificity of emotional reasoning was examined by comparing whether danger ratings and danger, safety, and index scores of an anxiety-specific story correlated higher with corresponding than with other anxiety symptoms. Finally, to investigate the developmental course of emotional and parent-based reasoning, a series of hierarchical regression analyses were carried out using $z$-transformed variables. In these analyses, index, safety or danger scores of the child or parent anxiety story were the dependent variables, whereas gender, age, either STAIC or RCADS anxiety (step 1), and the interaction of anxiety and age (step 2) were the predictors. Note that variables with significant skewness and kurtosis were normalized. 


\section{RESULTS}

\section{General Findings}

Before the main results are presented, several general issues should be pointed out. First, in correspondence with previous research, ${ }^{33}$ girls displayed significantly higher anxiety scores than boys did (see Table 2). No gender differences emerged for RCADS depression symptoms. Second, girls had higher danger ratings than boys for the child anxiety story [ts(503) $>2.4, P s<0.05]$, while for the parent anxiety story only the rating of the objective safety story with a positive response reached significance $[t(489)=2.4, P=0.01]$. No gender differences were present for safety, danger, and index scores $[t s(503)<1, P s=n s]$. Finally, internal consistencies of the measures were modest to excellent: for the anxiety and depression measures Cronbach's $\alpha$ s were between 0.66 and 0.92), and for the four versions of the child anxiety stories these values were between 0.56 and 0.73 .

\section{General Emotional Reasoning and Parent-based Reasoning Effects}

Table 3 shows means and standard deviations for the child anxiety story. As expected, the ANOVA showed that children evaluated objective danger stories as significantly more dangerous than objective safety stories $[F(1,504)=916.2, P<0.001]$. Furthermore, children found stories containing anxietyresponse information more dangerous than stories with positive-response information $[F(1$, 504)=149.6, $P<0.001]$. As the left panel of Figure 1 shows, children rated the objective danger and safety stories as more dangerous when containing anxiety-response information compared to positiveresponse information [both paired $t_{s}(504)>8.4, P_{s}<0.001$ ]. However, the magnitude of this emotional reasoning effect did not differ significantly between objective danger and safety stories [paired $t$ (504) $=1.8, P=0.2$; see Figure 1, left panel].

Table 3 also displays means and standard deviations the parent anxiety story. Again, the ANOVA revealed significant main effects of Situation $[F(1,490)=520.0, P<0.001]$ and Response $[F(1,490)=$ 164.2, $P<0.001]$, as well as a significant interaction effect $[F(1,490)=41.8, P<0.001]$. A Situation $\times$ Response interaction $[F(1,490)=5.57, P<0.025]$ showed that the magnitude of this emotional reasoning effect was somewhat larger in objective safety situations compared to objective danger situations [paired $t(490)=4.6, P<0.001$ ], although it was significant in both the safety and danger stories [paired $t s(490)>6.4, P s<0.001$; see Figure 1, right panel].

Thus, children not only showed a general emotional reasoning effect, they also exhibited parentbased reasoning in response to both objective safety and objective danger situations. Effects were more pronounced in the objective safety situation.

\section{Relationship of Anxiety and Depression with Emotional and Parent-based Reasoning}

To examine the relationship of emotional and parent-based reasoning with RCADS and STAIC, gender-corrected correlations were calculated (see Table 3). In general, both anxiety measures were significantly and positively associated with the danger ratings to the child anxiety story $(r$ s range from 0.40 to $\left.0.43, P_{s}<0.001\right)$ and the parent anxiety story ( $r$ s range from 0.18 to $\left.0.31, P_{s}<0.001\right)$. Most importantly, small but significant correlations emerged between anxiety measures and the safety and index scores of the child as well as the parent anxiety story ( $r$ s range from 0.09 to $0.16, P s<0.05$ ). However, no significant correlations were found between the anxiety measures and the danger scores of both stories.

In most cases, depression also correlated positively with danger ratings ( $r$ s range from 0.05 to 0.24 ), although it should be noted that correlations were considerably smaller than those obtained between anxiety and danger ratings. Most importantly, depression symptoms did not correlate with any of the danger, safety, and index scores (all $r s<0.08$ ).

To examine whether anxiety was more strongly associated with emotional and parent-based reasoning compared to depression symptoms, tests for comparing correlation coefficients were carried out. ${ }^{34}$ As can be seen in Table 3, danger ratings for both the child and parent anxiety stories generally were more substantially correlated with both anxiety measures than with depression. This was also the case for the safety score of the child anxiety story.

In addition, partial correlations were computed in order to investigate whether anxiety and depression were independently associated with emotional and parent-based reasoning. When controlling for anxiety (i.e., RCADS, STAIC, or both), correlations between depression and child and parent danger ratings and scores significantly attenuated and were no longer significant in the expected direction $(r \mathrm{~s}$ 
between -0.15 and 0.05 ). However, when controlling for depression, the significant correlations between both anxiety indices and the child and parent anxiety story danger ratings and scores remained substantial ( $r$ s between 0.10 and 0.39 ), except for the correlations with the index score of the parent anxiety story (both $r s<0.09, n s$ ).

\section{Content-specificity of Emotional Reasoning}

As can be seen in Table 4, no support was found for the notion that the tendency to rely on subjective-response information when estimating danger is anxiety-specific. That is, the few significant differences that emerged were either opposite to the predictions (e.g., the safety score of the social anxiety story correlated stronger with RCADS generalized anxiety than with RCADS social anxiety) or irrelevant (e.g., RCADS generalized anxiety correlated stronger with the safety score of the social anxiety story than with that of the separation anxiety story).

\section{Emotional and Parent-based Reasoning as a Function of Age and Anxiety}

To find out whether emotional and parent-based reasoning effects persist with age in anxious children but wane with age in non-anxious children, 12 regressions were carried out. The danger, safety or index score of the child or parent anxiety story was predicted by gender, age, and RCADS or STAIC scores (step 1), and by the interaction of RCADS/STAIC $\times$ age (step 2). After Bonferronicorrection $(\alpha / 12)$ had been applied, both RCDAS and STAIC significantly predicted the safety score of the child anxiety story, whereas only the RCADS significantly predicted the safety as well as index score of the parent-anxiety story. No significant effects of age or gender on emotional or parent-based reasoning emerged. The only significant interaction effect was between age and STAIC, predicting the index score of the parent anxiety story $(P<0.05 / 12)$. Inspection of this interaction indicated that, in contrast with the prediction, the general parent-based reasoning effect significantly decreased with age in high trait anxious children, whereas it increased with age in low trait anxious children.

\section{DISCUSSION}

The present study investigated emotional and parent-based reasoning in children. Results can be summarized as follows. First, evidence was found that children generally displayed emotional and parent-based reasoning. More specifically, children not only used objective information to determine the dangerousness of a situation, but also relied on anxiety- and positive-response information. These effects were demonstrated in both objective safety and objective danger situations. Second, anxiety was more substantially associated with most of the emotional and parent-based reasoning scores than depression, and this was especially true for scores pertaining to objective-safety stories. No evidence was found that the relationships between anxiety, and emotional and parent-based reasoning were content-specific. Last, no evidence was found for the hypothesis that emotional and parent-based reasoning remain stable with age in high anxious children, but decrease with age in low anxious children.

The emotional reasoning effect emerged not only in objective safety situations, like in Muris et al.' ${ }^{1}$ study, but also in objective danger situations. Several differences between the stories of both studies may explain this discrepancy. First, the anxiety-response information in the Muris et al. study only involved a physical symptom (e.g., trembling), whereas an explicit anxiety-affect (e.g., being scared) was added to the physical symptom in the present study. ${ }^{10}$ Second, Muris et al.'s control stories contained no anxiety-response information, whereas control stories in the current study contained positiveresponse information in the form of positive affect (e.g., feeling happy) and positive behavior (e.g., laughing). These modifications may have made the present experiment more sensitive to tap emotional reasoning effects, and may thus explain why emotional reasoning emerged in both objective safety and objective danger stories.

The present findings indicate that children not only rely on their own emotional response when deciding whether threat is imminent (i.e., emotional reasoning), but also on their mother's response. This general parent-based reasoning effect adds to the evidence on social referencing ${ }^{21}$ and parental influences on cognitive bias in children. ${ }^{35,36}$ Moreover, this finding is consistent with an emerging body of research that supports the role of modeling and negative information in the development of childhood anxiety ${ }^{1,22,37}$ and avoidance behavior. ${ }^{38}$ Of course, the present investigation did not directly address the relationship between parent-based reasoning and modeling or social referencing. For 
example, one way in which these phenomena may be different is the extend to which intrapersonal processes like cognition are hypothesized to be relevant. In addition, the hypothesis that modeling, social referencing, or parent-based reasoning is associated with anxiety in children presupposes that parent anxiety, when present, will be expressed in certain behavioral responses. The mutual connection between these variables might be of considerable interest for future research.

The general emotional reasoning effect that was found in the present sample is in line with the results of Muris et al. ${ }^{1}$ In contrast, Arntz et al. ${ }^{10}$ found that normal adults only use objective danger information to rate threat, and do not rely on anxiety-response information. As mentioned in the introduction, developmental issues may explain this discrepancy. Emotional reasoning may be a normal phenomenon in young children, which gradually disappears as children become able to discriminate between objective danger information and subjective response information. When anxious children fail to master this ability, emotional reasoning persists. Some evidence for such a developmental pattern has been found with attentional bias. ${ }^{18,19}$ Present findings did not support this hypothesis, although it should be pointed out that all children in the present study were still rather young (i.e., younger than 14 years). Emotional reasoning may not wane until later in adolescence. ${ }^{1}$ The current study did find a significant age $\times$ anxiety interaction for parent-based reasoning. That is, general parent-based reasoning decreased in high trait anxious children, but remained stable in low trait anxious children. It is plausible to assume that high trait anxious children gradually rely less on their mother's anxiety response as they get older, and increasingly rely on their own response instead.

Consistent with previous studies, ${ }^{1,10}$ high levels of trait anxiety, and anxiety and depression symptoms were significantly associated with the tendency to use personal and parental response information when rating the dangerousness of the situations. These associations were significantly stronger for anxiety than for depression. Moreover, the relationship between anxiety, on the one hand, and emotional and parent-based reasoning, on the other hand, seemed to be independent of depression. Thus, although results indicated that emotional and parent-based reasoning are anxiety-related phenomena, it should also be mentioned that specific anxiety complaints were not specifically linked to emotional reasoning in situations relevant to these complaints. In other words, no evidence was found that the tendency to infer danger from subjective anxiety response information was contentspecific. $^{10}$

The present study has several limitations. First, the current sample consisted of normal children that did not meet the diagnostic criteria for an anxiety disorder. It would be worthwhile to replicate these findings in a sample of clinically referred children. Second, this sample contained a relatively large proportion of girls. However, the findings are in line with Muris et al., ${ }^{1}$ who studied a sample with a more balanced gender distribution. Third, emotional and parent- based reasoning were assessed by means of a paper-and-pencil assessment. Future studies should further establish the ecological validity of emotional and parent-based reasoning by using experimental analogues of the task. This could also resolve some of the drawbacks of the correlational nature of present study, because one could actually examine whether emotional responding of children or their parents directly produce changes in the child's level of fear to stimuli or situations. Fourth, with respect to parent-based reasoning only the tendency to rely on maternal response information was investigated, which may differ from children's tendency to rely on paternal response information. In addition, it might be interesting to examine nonparental sources of response information, such as peers or familiar and unfamiliar adults. Fifth, because children's age range was limited, the developmental pattern of emotional and parent- based reasoning in children and adolescents could not be fully clarified. Finally, a possible alternative explanation of the inflated danger ratings in stories with anxiety symptoms is that they did not result from emotional reasoning, but from general emotion or ground and ceiling effects. To conclude, the present study strongly suggests that emotional and parent-based reasoning are normal phenomena in children, and adds to the extant body of research investigating the development of anxiety.

\section{SUMMARY}

Cognitive theory of childhood fear posits that anxiety in children is associated with various cognitive distortions. The focus of current study was on two types of anxiety-related interpretation biases in children, viz. emotional and parent-based reasoning. These phenomena can be defined as respectively the tendency to estimate danger on the basis of personal and parental response information. Children 
first completed measures of anxiety and depression. Next, they were asked to provide danger ratings of stories in which objective danger and objective safety information, and anxiety- and positiveresponse information were systematically varied. Results showed that children generally not only rely on their own emotional responding when deciding whether a situation is dangerous, but also on emotional responding of their parent. Both effects were moderately but significantly correlated with anxiety. Although both effects were more closely associated with anxiety than with depression, no content- specific relationship with anxiety emerged. Although the present findings are in line with previous studies investigating this type of cognitive distortion in children, prospective research is required to examine the role of emotional and parent-based reasoning in the development of anxiety.

\section{ACKNOWLEDGEMENTS}

We would like to thank Annemarie Boogerd and Niek van Bruggen for their assistance with the data collection. We are also very grateful to the staff and children of the schools for their cooperation to this study. 
TABLES AND FIGURES

Table 1

Anxiety and positive responses for the four stories

\begin{tabular}{|c|c|c|}
\hline Story & Anxiety Response & Positive Response \\
\hline Social phobia & $\begin{array}{l}\text { You feel embarrassed and your } \\
\text { heart is in your mouth. }\end{array}$ & $\begin{array}{l}\text { You don't care about it and } \\
\text { still feel good and at ease. }\end{array}$ \\
\hline $\begin{array}{l}\text { Separation } \\
\text { anxiety }\end{array}$ & $\begin{array}{l}\text { Suddenly feel afraid and } \\
\text { start to tremble. }\end{array}$ & $\begin{array}{l}\text { You smile and wave to your } \\
\text { parents. }\end{array}$ \\
\hline $\begin{array}{l}\text { Generalized } \\
\text { anxiety }\end{array}$ & $\begin{array}{l}\text { You become frightened and } \\
\text { feel sick. }\end{array}$ & $\begin{array}{l}\text { You remain calm and feel } \\
\text { good. }\end{array}$ \\
\hline $\begin{array}{l}\text { Parent } \\
\text { anxiety }\end{array}$ & $\begin{array}{l}\text { It frightens your mum and } \\
\text { her legs start to tremble. }\end{array}$ & $\begin{array}{l}\text { Your mum looks happy, and } \\
\text { she smiles and waves to } \\
\text { her friend in the car. }\end{array}$ \\
\hline
\end{tabular}

Note: Full stories can be obtained from the first author.

Table 2

Mean scores (standard deviations), gender differences, and reliability coefficients for the RCADS scales and the STAIC

\begin{tabular}{lrrccc}
\hline & Total & Boys & Girls & $\begin{array}{c}N \\
\text { (boys, girls) }\end{array}$ & Cronbach's $\alpha$ \\
\hline RCADS & & & & & \\
Total score & $15.3(9.4)$ & $12.1(7.9)$ & $15.9(9.6)^{*}$ & 84,423 & 0.92 \\
$\quad \begin{array}{l}\text { Generalized } \\
\quad \text { anxiety }\end{array}$ & $5.0(3.1)$ & $3.9(2.7)$ & $5.2(3.2)^{*}$ & 83,422 & 0.83 \\
$\quad \begin{array}{l}\text { Separation } \\
\quad \text { anxiety }\end{array}$ & $2.7(2.8)$ & $2.0(2.3)$ & $2.9(2.9)^{*}$ & 84,420 & 0.80 \\
$\quad \begin{array}{l}\text { Social anxiety } \\
\text { Depression }\end{array}$ & $4.0(2.8)$ & $3.1(2.5)$ & $4.1(2.9)^{*}$ & 83,414 & 0.75 \\
$\quad 3.5(2.1)$ & $3.1(1.8)$ & $3.6(2.2)$ & 82,411 & 0.66 \\
$\quad$ STAmptoms & & & & & \\
$\quad$ STAIC & $32.3(7.9)$ & $29.8(6.8)$ & $32.8(8.0)^{*}$ & 84,422 & 0.92 \\
\hline
\end{tabular}

Notes: $\mathrm{RCADS}=$ Revised Children's Anxiety and Depression Scale, $\mathrm{STAIC}=$ trait anxiety scale of the State-Trait Anxiety Inventory for Children. *Significant gender differences at $P<0.01$. 


\section{Table 3}

Means (standard deviations) for story-based scores, and correlation (corrected for gender) between RCADS anxiety, depression and STAIC, on the one hand, and danger ratings, danger, safety, and index scores for the child anxiety story $(N=487)$ and the parent anxiety story $(N=473)$, on the other hand

\begin{tabular}{|c|c|c|c|c|c|}
\hline Story & Danger Rating & $\begin{array}{c}\text { Mean } \\
(S D)\end{array}$ & $\begin{array}{l}\text { RCADS } \\
\text { Anxiety }\end{array}$ & $\begin{array}{c}\text { RCADS } \\
\text { Depression }\end{array}$ & STAIC \\
\hline \multirow[t]{7}{*}{$\begin{array}{l}\text { Child } \\
\text { Anxiety }\end{array}$} & $\begin{array}{l}\text { Danger/anxiety } \\
\text { response }\end{array}$ & $4.5(2.3)$ & $0.43_{\mathrm{a}}^{* *}$ & $0.24_{\mathrm{b}}^{*} *$ & $0.43_{\mathrm{a}}^{* * *}$ \\
\hline & $\begin{array}{l}\text { Danger/positive } \\
\text { response }\end{array}$ & $4.0(2.2)$ & $0.43_{\mathrm{a}}^{* *}$ & $0.21_{\mathrm{b}}^{*} *$ & $0.41_{\mathrm{a}}^{* *}$ \\
\hline & $\begin{array}{l}\text { No danger/anxiety } \\
\text { response }\end{array}$ & $3.0(2.1)$ & $0.43_{\mathrm{a}}^{* *}$ & $0.22_{\mathrm{b}}^{*} *$ & $0.42_{\mathrm{a}}^{* *}$ \\
\hline & $\begin{array}{l}\text { No danger/positive } \\
\text { response }\end{array}$ & $2.4(1.7)$ & $0.40_{\mathrm{a}}^{* *}$ & $0.24_{\mathrm{b}}^{*} *$ & $0.40_{\mathrm{a}}^{* * *}$ \\
\hline & Danger score & $0.5(1.4)$ & $0.03_{\mathrm{a}}$ & $0.06_{\mathrm{a}}$ & $0.06_{\mathrm{a}}$ \\
\hline & Safety score & $0.6(1.3)$ & $0.16_{\mathrm{a}}^{* *}$ & $0.06_{b}$ & $0.16_{\mathrm{a}}^{* *}$ \\
\hline & Index score & $0.6(1.1)$ & $0.12_{\mathrm{a}}^{*}$ & $0.07_{\mathrm{a}}$ & $0.14_{\mathrm{a}}^{*}$ \\
\hline \multirow[t]{7}{*}{$\begin{array}{l}\text { Parent } \\
\text { Anxiety }\end{array}$} & $\begin{array}{l}\text { Danger/anxiety } \\
\text { response }\end{array}$ & $5.9(3.1)$ & $0.31_{\mathrm{a}}^{* *}$ & $0.11_{\mathrm{b}}^{*}$ & $0.29 * *$ \\
\hline & $\begin{array}{l}\text { Danger/positive } \\
\text { response }\end{array}$ & $4.9(3.0)$ & $0.25_{\mathrm{a}}^{* *}$ & $0.05_{\mathrm{b}}$ & 0.27 粮 \\
\hline & $\begin{array}{l}\text { No danger/anxiety } \\
\text { response }\end{array}$ & $3.8(2.8)$ & $0.26_{\mathrm{a}}^{* *}$ & $0.13_{\mathrm{b}}^{*}$ & $0.25_{\mathrm{a}}^{* *}$ \\
\hline & $\begin{array}{l}\text { No danger/positive } \\
\text { response }\end{array}$ & $2.2(2.1)$ & $0.20 * * *$ & $0.90_{\mathrm{b}}$ & $0.18_{\mathrm{ab}}{ }^{*}$ \\
\hline & Danger score & $0.9(3.0)$ & $0.07 \mathrm{a}$ & $0.06_{\mathrm{a}}$ & $0.04 \mathrm{a}$ \\
\hline & Safety score & $1.6(2.7)$ & $0.12_{a}^{*}$ & $0.06_{a}$ & $0.11_{\mathrm{a}}^{*}$ \\
\hline & Index score & $1.3(2.3)$ & $0.11_{\mathrm{a}}^{*}$ & $0.08_{\mathrm{a}}$ & $0.09_{\mathrm{a}}^{*}$ \\
\hline
\end{tabular}

Notes: RCADS = Revised Children's Anxiety and Depression Scale, STAIC = trait anxiety scale of the State-Trait Anxiety Inventory for children. Correlations in the same row that do not share the same subscript differ at $P<0.05 / 3$. ${ }^{*} P<0.01$, *** $P<0.001$, two-tailed. 
Morren, M., Muris, P., Kindt, $M$.

Emotional reasoning and parent-based reasoning in normal children.

Child Psychiatry and Human Development: 35, 2004, nr. 1, p. 3-20
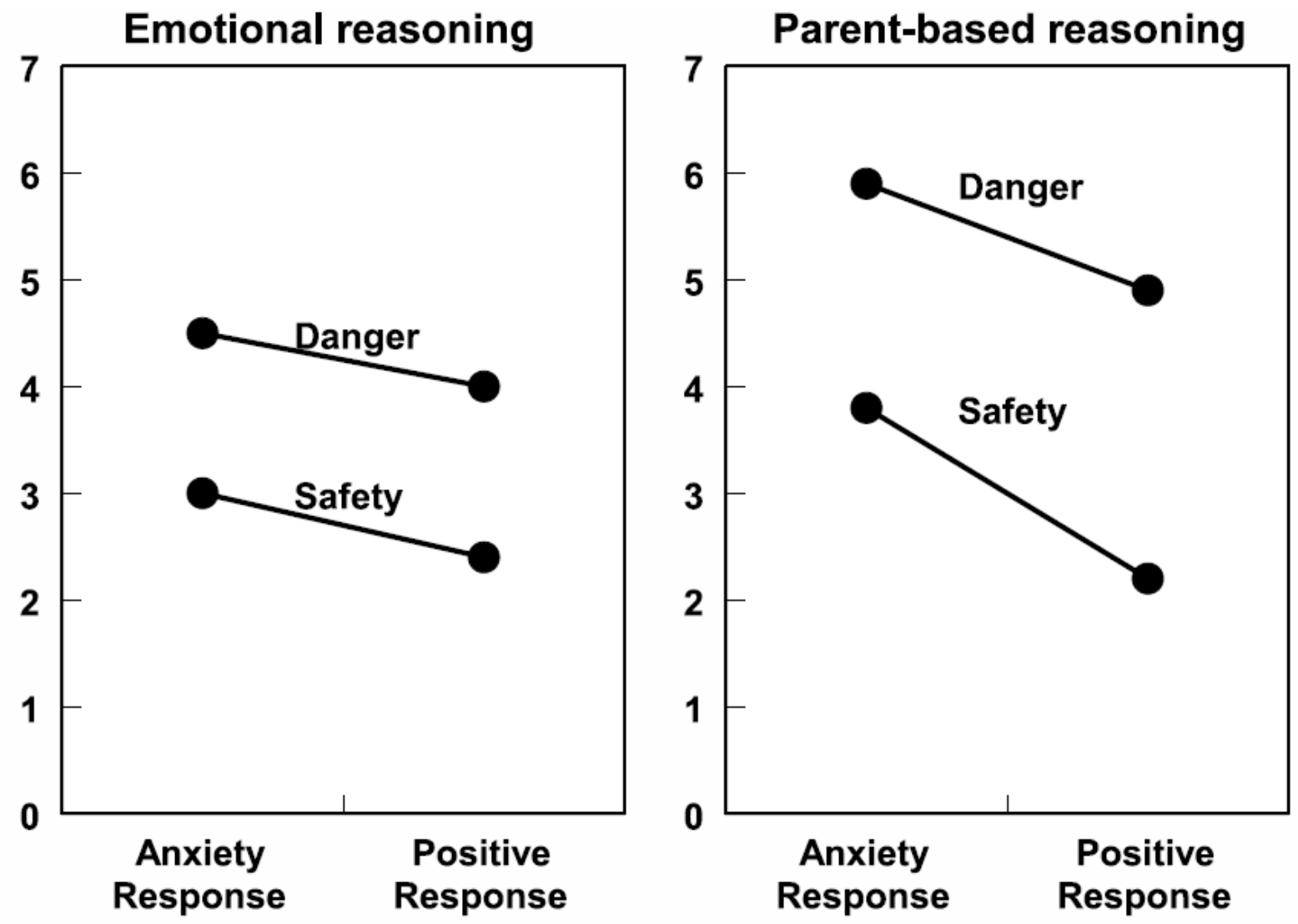

Figure 1. General emotional reasoning effect (left panel; $N=505$ and parent-based reasoning effect (right panel; $N=490$ ): mean danger ratings for objective danger and objective safety stories with anxiety- or positiveresponse information as computed for the total sample. 
Table 4

Correlations (corrected for gender) between RCADS generalized anxiety, separation anxiety, and social anxiety, on the one hand, and danger ratings, danger, safety, index scores of the generalized anxiety, separation anxiety, and social anxiety story

\begin{tabular}{|c|c|c|c|c|}
\hline Story & $\begin{array}{l}\text { Danger } \\
\text { Rating }\end{array}$ & $\begin{array}{c}\text { Generalized } \\
\text { Anxiety }\end{array}$ & $\begin{array}{c}\text { Separation } \\
\text { Anxiety }\end{array}$ & $\begin{array}{c}\text { Social } \\
\text { Anxiety }\end{array}$ \\
\hline \multirow[t]{7}{*}{$\begin{array}{l}\text { Generalized } \\
\text { Anxiety }\end{array}$} & $\begin{array}{l}\text { Danger/anxiety } \\
\text { response }\end{array}$ & $0.30 * *$ & $0.33^{* *}$ & $0.27 * *$ \\
\hline & $\begin{array}{l}\text { Danger/positive } \\
\text { response }\end{array}$ & $0.27 * *$ & $0.30 * *$ & $0.32 * *$ \\
\hline & $\begin{array}{l}\text { No danger/anxiety } \\
\text { response }\end{array}$ & $0.23 * *$ & $0.25^{* *}$ & $0.24 * *$ \\
\hline & $\begin{array}{l}\text { No danger/positive } \\
\text { response }\end{array}$ & $0.23 *$ & $0.28 * *$ & $0.24^{* * *}$ \\
\hline & Danger score & 0.04 & 0.06 & -0.05 \\
\hline & Safety score & $0.09^{*}$ & 0.05 & $0.10^{*}$ \\
\hline & Index score & $0.09^{*}$ & 0.08 & 0.03 \\
\hline \multirow[t]{7}{*}{$\begin{array}{l}\text { Separation } \\
\text { Anxiety }\end{array}$} & $\begin{array}{l}\text { Danger/anxiety } \\
\text { response }\end{array}$ & $0.27 * *$ & $0.29 * *$ & $0.25 * *$ \\
\hline & $\begin{array}{l}\text { Danger/positive } \\
\text { response }\end{array}$ & $0.27 * *$ & $0.27 *$ & $0.21^{*}$ \\
\hline & $\begin{array}{l}\text { No danger/anxiety } \\
\text { response }\end{array}$ & $0.23 * *$ & $0.20 * *$ & $0.23 * *$ \\
\hline & $\begin{array}{l}\text { No danger/positive } \\
\text { response }\end{array}$ & $0.24 * *$ & $0.22^{* *}$ & $0.22 * *$ \\
\hline & Danger score & -0.01 & 0.00 & 0.03 \\
\hline & Safety score & -0.01 & -0.00 & 0.03 \\
\hline & Index score & -0.02 & 0.00 & 0.04 \\
\hline \multirow[t]{7}{*}{$\begin{array}{l}\text { Social } \\
\text { Anxiety }\end{array}$} & $\begin{array}{l}\text { Danger/anxiety } \\
\text { response }^{\mathrm{a}}\end{array}$ & $0.24 * *$ & $0.26^{* * *}$ & $0.26^{* * *}$ \\
\hline & $\begin{array}{l}\text { Danger/positive } \\
\text { response }^{\mathrm{a}}\end{array}$ & $0.22^{* * *}$ & $0.24^{* * *}$ & $0.30 * *$ \\
\hline & $\begin{array}{l}\text { No danger/anxiety } \\
\text { response }^{\mathrm{a}}\end{array}$ & $0.25 * *$ & $0.30 * *$ & $0.27 * *$ \\
\hline & $\begin{array}{l}\text { No danger/positive } \\
\text { response }^{\mathrm{a}}\end{array}$ & $0.20 * *$ & $0.22^{* *}$ & $0.22 * *$ \\
\hline & Danger score & 0.06 & 0.05 & -0.00 \\
\hline & Safety score & $0.13^{*}$ & $0.17 * *$ & $0.14^{*}$ \\
\hline & Index score & $0.12^{*}$ & $0.14^{*}$ & 0.08 \\
\hline
\end{tabular}

Notes: $N=460$. ${ }^{*} P<0.01,{ }^{*} P<<0.001$, two-tailed. 


\section{REFERENCES}

1. Muris $\mathrm{P}$, Merckelbach $\mathrm{H}$, Van Spauwen I: The emotional reasoning heuristic in children. Behav Res Ther 41: 261-272, 2003.

2. Gullone E: The development of normal fear: A century of research. Clin Psychol Rev 20: 429$451,2000$.

3. Ollendick TH, King NJ, Muris, P: Fears and phobias in children: phenomenology, epidemiology, and aetiology. Child Adolesc Ment Health 7: 98-106, 2002.

4. Costello EJ, Angold A: Epidemiology. In: Anxiety disorders in children and adolescents, ed. March JS. New York: Guilford, 1995, pp. 109-124.

5. Am Acad Child Adolesc Psychiatry: Practise parameters for assessment and treatment of children and adolescents with anxiety disorders. J Am Acad Child Adolesc Psychiatry 36(Suppl.): 69S-84S.

6. Kendall PC: Toward a cognitive-behavioral model of child psychopathology and a critique of related interventions. J Abn Child Psychol 13: 357-372, 1985.

7. Crick NR, Dodge KA: A review and reformulation of social-information processing mechanisms in children's social adjustment. Psychol Bull 115: 74-101, 1994.

8. Daleiden EL, Vasey MW: An information-processing perspective on childhood anxiety. Clin Psychol Rev 17: 407-429, 1997.

9. Beck AT, Emery G, Greenberg RL: Anxiety disorders and phobias. A cognitive perspective. New York: Basic Books, 1985.

10. Arntz A, Rauner M, Van den Hout M: "If I feel anxious, there must be danger": Exconsequentia reasoning in inferring danger in anxiety disorders. Behav Res Ther 33: 917-925, 1995.

11. Engelhard IM, Macklin ML, McNally RJ, Van den Hout MA, Arntz A: Emotionand intrusionbased reasoning in Vietnam veterans with and without posttraumatic stress disorder. Behav Res Ther 39: 1339-1348, 2001.

12. Engelhard IM, Van den Hout MA, Arntz A, McNally RJ: A longitudinal study of "intrusion-based reasoning" and posttraumatic stress disorder after exposure to a train disaster. Behav Res Ther 40: 1415-1424, 2002.

13. Muris $\mathrm{P}$, Merckelbach $\mathrm{H}$, Schepers $\mathrm{S}$, Meesters $\mathrm{C}$ : Anxiety, threat perception abnormalities, and emotional reasoning in nonclinical Dutch children. J Clin Child Adolesc Psychol, 32: 453459, 2003.

14. Muris $\mathrm{P}$, Merckelbach $\mathrm{H}$ : The etiology of childhood specific phobia: A multifactorial model. In: The developmental psychopathology of anxiety, ed. Vasey MW, Dadds MR. Oxford: Oxford University Press, 2001, pp. 355-385.

15. Muris $\mathrm{P}$, Bodden $\mathrm{D}$, Merckelbach $\mathrm{H}$, Ollendick TH, King N: Fear of the beast: A prospective study on the effects of negative information on childhood fear. Behav Res Ther 41: 195-208, 2003.

16. Kindt M, Brosschot JF, Everaerd W: Cognitive processing bias of children in a real life stress situation and a neutral situation. J Exp Child Psychol 64: 79- 97, 1997.

17. Kindt M, Bierman D, Brosschot JF: Cognitive bias in spider fear and control children: Assessment of emotional interference by a card format and a singletrial format of the Stroop task. J Exp Child Psychol 66: 163-179, 1997.

18. Kindt $M$, Van den Hout M, De Jong P, Hoekzema B: Cognitive bias for pictorial and linguistic threat cues in children. J Psychopathol Behav Assess 22: 201-219, 2000.

19. Morren M, Kindt M, Van den Hout M, Boogerd A: Processing bias and spider fear in children aged 7 to 13 years: the role of cognitive inhibition, trait anxiety, and attentional control: submitted.

20. Feinman S: Social referencing and the social construction of reality in infancy. New York: Plenum Press, 1992.

21. Camras LA, Sachs VB: Social referencing and caretaker expression in a day care setting. Inf Behav Dev 14: 27-36, 1991.

22. Gerull FC, Rapee RM: Mother knows best: Effects of maternal modelling on the acquisition of fear and avoidance behaviour in toddlers. Behav Res Ther 40: 279-287, 2002.

23. Gunnar MR, Stone C: The effects of positive maternal affect on infant responses to pleasant, ambiguous, and fear-provoking toys. Child Dev 55: 1231-1236, 1984.

24. Zarbatany L, Lamb ME: Social referencing as a function of information source: Mothers versus strangers. Inf Behav Dev 8: 25-33, 1985.

25. Rachman SJ: The conditioning theory of fear acquisition: A critical examination. Behav Res Ther 15: 375-387, 1977. 
26. Rachman SJ: Neoconditioning and the classical theory of fear acquisition. Clin Psychol Rev 11: 155-173, 1991.

27. King NJ, Gullone E, Ollendick TH: Etiology of childhood phobias: Current status of Rachman's three pathways theory. Behav Res Ther 36: 298-309, 1998.

28. Morren M, Kindt M, Van den Hout M, Van Kasteren $\mathrm{H}$ : Anxiety and the processing of threat in children aged 7-11: Further examination of the cognitive inhibition hypothesis. Behav Change 20: 131-142, 2003.

29. Kindt M, Brosschot JF, Muris, P: Spider Phobia Questionnaire for Children (SPQ-C): A psychometric study and normative data. Behav Res Ther 34: 277- 282, 1996.

30. Muris P, Meesters C, Schouten E: A Brief Questionnaire of DSM-IV-defined anxiety and depression symptoms among children. Clin Psychol Psychother 9: 430- 442, 2002.

31. Chorpita BF, Yim L, Moffitt C, Umemoto LA, Francis SE: Assessment of symptoms of DSM-IV anxiety and depression in children: A revised child anxiety and depression scale. Behav Res Ther 38: 835-855, 2001.

32. Spielberger CD: Manual for the State-Trait Anxiety Inventory for Children. Palo Alto, CA: Consulting Psychologists Press, 1973.

33. Craske MG: Fear and anxiety in children and adolescents. Bull Menninger Clin 62: A4-A36, 1997.

34. Meng XL, Rosenthal R, Rubin DB: Comparing correlated correlation coefficients. Psychol Bull 111: 172-175, 1992.

35. Barrett PM, Rapee RM, Dadds MM, Ryan SM: Family enhancement of cognitive style in anxious and aggressive children. J Abn Child Psychol 24: 187-203, 1996.

36. Chorpita BF, Albano AM, Barlow DH: Cognitive processing in children: Relation to anxiety and family influences. J Clin Child Psychol 25: 170-176, 1996.

37. Field AP, Argyris NG, Knowles KA: Who's afraid of the big bad wolf: A prospective paradigm to test Rachman's indirect pathways in children. Behav Res Ther 39: 1259-1276, 2001.

38. Silverman WK, Cerny JA, Nelles, WB, Burke AE. Behavior problems in children of parents with anxiety disorders. J Am Acad Child Adolesc Psychiatry 27: 779-784, 1988. 